\title{
Efeito de níveis de cálcio e sombreamento em plantas de soja sobre a infecção por Phakopsora pachyrhizi
}

\author{
Daniel Debona, Lucas Navarini, Diego D. Favera \& Ricardo S. Balardin \\ Departamento de Defesa Fitossanitária, Centro de Ciências Rurais, Universidade Federal de Santa Maria, 97111-970, Santa \\ Maria, RS, Brasil
}

Autor para correspondência: Ricardo S. Balardin, e-mail: balardin@balardin.com

\section{RESUMO}

O objetivo desse trabalho foi avaliar o efeito de sete doses de cálcio (zero; 49,5: 99,0: 148,5: 198,0; 247,5 e 297,0 kg.ha-1) e dois níveis de sombreamento (sombra, pleno sol) em um sistema fatorial de 7x2.

Palavras chave: manejo de doença, ferrugem, Glycine max.

\section{ABSTRACT \\ Effect of calcium supply and shading on Phakopsora pachyrhizi infection}

The objective of this work was to evaluate the effect of seven calcium rates (zero; 49,5: 99,0: 148,5: 198,0; 247,5 e 297,0 kg.ha-1) and two levels of shading (shading, shadeless) in a 7x2 factorial system.

Keywords: disease management, rust fungi, Glycine max.

A ferrugem asiática constitui-se na principal doença da cultura da soja (Glycine max). Condições climáticas favoráveis ao patógeno na maioria das regiões aliadas à sua alta virulência e velocidade de dispersão são fatores que tornam esta doença altamente agressiva. Acredita-se que o fornecimento de nutrientes de forma equilibrada possibilite ao hospedeiro uma maior expressão de seus mecanismos de defesa de forma a contribuir para a redução de severidade da doença. O trabalho teve por objetivo avaliar o efeito de níveis de suplementação com $\mathrm{Ca}$ e de sombreamento na severidade da ferrugem asiática da soja.

O ensaio foi desenvolvido em casa de vegetação da Universidade Federal de Santa Maria, Santa Maria RS, entre dezembro de 2005 e fevereiro de 2006, sendo conduzido em delineamento inteiramente casualizado com quatro repetições. Sementes da cultivar 'AL 83' foram semeadas em vasos plásticos contendo substrato composto de areia lavada, solo argiloso e casca de arroz não-carbonizada $(3: 1: 2)$. Os 14 tratamentos foram dispostos em esquema fatorial $7 \times 2$ com sete níveis de Ca (zero; 49,5: 99,0: 148,5: 198,0; 247,5 e 297,0 kg.ha$\left.{ }^{1}\right)$, fornecidos na forma de calcário calcítico finamente moído (filler), e dois níveis de sombreamento (com e sem). Os níveis de sombreamento foram obtidos pelo espaçamento entre as hastes das plantas. Nos tratamentos não-sombreados a distância entre hastes foi de $50 \mathrm{~cm} \mathrm{e}$ nos sombreados, de $30 \mathrm{~cm}$. Estes, ao atingir estádio $\mathrm{V}_{3}$, foram circundados por vasos contendo plantas de soja de idade fisiológica mais avançada a fim de produzir autosombreamento no interior do dossel.

A inoculação com esporos de Phakopsora pachyrhizi Syd. \& P. Syd. foi realizada no estádio $\mathrm{V}_{7}$ na concentração de $2 \times 10^{5}$ esporos. $\mathrm{mL}^{-1}$. Foi avaliada a severidade de ferrugem aos 7, 14 e 21 dias após a inoculação utilizando escala proposta por Godoy et al. (2006). Os dados foram submetidos à análise de variância, sendo a análise complementar realizada por regressão do fator quantitativo dentro de cada fator qualitativo.

Tanto o sombreamento quanto o suprimento com $\mathrm{Ca}$ afetaram a resposta das plantas de soja ao ataque do fungo. Para os tratamentos sombreados, a severidade final da ferrugem cresceu quadraticamente com a elevação na dose de Ca de 49,5 para 247,5 kg.ha-1, com posterior diminuição (Figura 1). A severidade observada na dose de 247,5 foi de $27,50 \%$ (ponto de máximo na função matemática). Nos tratamentos não-sombreados houve redução na severidade final da doença de 16,25\% para 9,75\% com o incremento nas doses de $\mathrm{Ca}$ de 49,5 a 247,5 kg.ha ${ }^{-1}$ (ponto de mínimo da função), seguido de elevação na severidade (Figura 2). O maior espaçamento provavelmente tenha possibilitado uma maior incorporação de Ca na forma de pectatos na parede celular, através do aumento da taxa fotossintética, dificultando fisicamente a penetração e colonização do patógeno. Um manejo que otimize a penetração de radiação solar no dossel da planta aliado a uma nutrição adequada contribui para a redução da severidade da ferrugem da soja. 


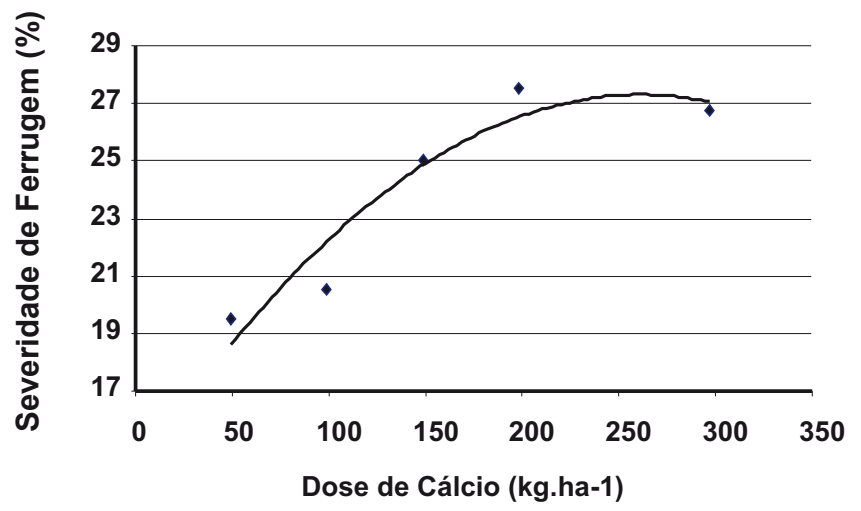

$\bullet$ com sombreamento $y=-0,00019 x^{2}+0,10104 x+14,09536$
$R^{2}=0,91082$

FIG. 1 - Severidade final da ferrugem da soja em função de níveis de cálcio para os tratamentos sombreados.

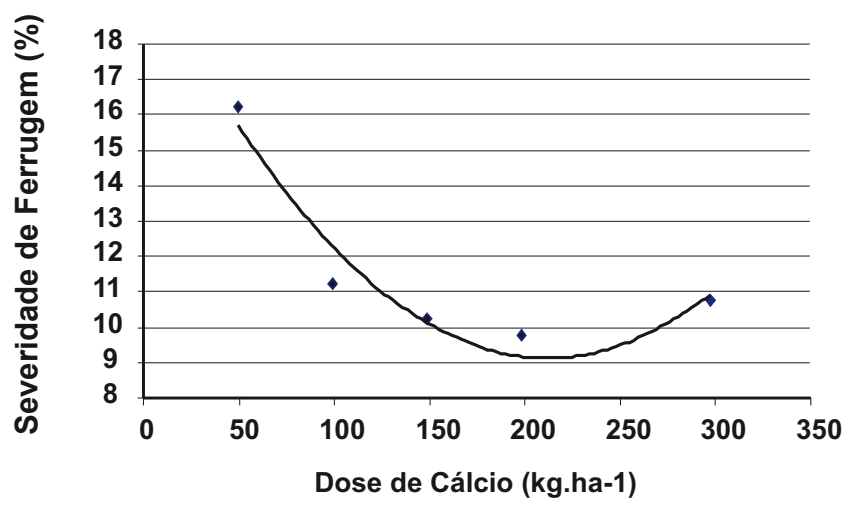

- sem sombreamento $y=0,00025 x^{2}-0,10593 x+20,34278$
$R^{2}=0,93535$

FIG. 2 - Severidade final da ferrugem da soja em função de níveis de cálcio para os tratamentos não-sombreados.

\section{REFERÊNCIAS BIBLIOGRÁFICAS}

Godoy C, Koga LJ, Canteri MG (2006) Diagrammatic scale for assessment of soybean rust severity. Fitopatologia Brasileira 31:6368.

Recebido 29 Setembro 2007 - Aceito 15 Setembro 2008 - TPP 7066 Editor Associado: Edson A. Pozza 